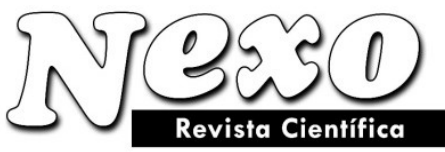

ISSN-E 1995-9516

Universidad Nacional de Ingeniería http://revistas.uni.edu.ni/index.php/Nexo http://dx.doi.org/10.5377/nexo.v31i01.6450

Vol. 31, No. 01, pp. 01-15/Junio 2018

(c) $(i)(5)$

\title{
HERRAMIENTAS MOLECULARES PARA ESTUDIAR LAS AGUAS DE CONSUMO HUMANO DEL CACAO, MOZONTE, NUEVA SEGOVIA, NICARAGUA
}

\section{MOLECULAR TOOLS FOR STUDY THE HUMAN'S DRINKABLE WATER FROM CACAO, MOZONTE, NUEVA SEGOVIA, NICARAGUA}

\author{
L.A Páramo-Aguilera ${ }^{1 *}$, T.S Garmendia ${ }^{2}$ y J. Villalta-Domínguez ${ }^{3}$. \\ ${ }^{1 *}$ Programa de Investigación Estudios Nacionales y Servicios Ambientales (PIENSA), Universidad Nacional de \\ Ingeniería, UNI. Avenida Universitaria, frente a la UCA. Tel. 87594165. E-mail: lparamo2014@gmail.com \\ ${ }^{2,3}$ Facultad de Ingeniería Química. Universidad Nacional de Ingeniería, UNI.
}

(recibido/received: 09-02-2018; aceptado/accepted: 01-06-2018)

\section{RESUMEN}

Se determinaron los principales indicadores microbiológicos de la calidad del agua para consumo humano por medio del Numero Más Probable y se realizó el aislamiento e identificación por vía morfológica y molecular de los microorganismos aislados de la biopelícula existente en el punto de captación del acuífero de la comunidad El Cacao, municipio Mozonte, Nueva Segovia. Muestreando en 3 puntos: captación, almacenamiento y llave de chorro, y realizando análisis del número más probable (NMP), aislamientos, purificación y pruebas morfológicas en los laboratorios del Programa de Investigación Estudios Nacionales y Servicios Ambientales (PIENSA) de la Universidad Nacional de Ingeniería. La secuenciación microbiana se encargó a Biología Molecular de la Universidad Centroamericana. Los resultados indican contaminación por coliformes totales, fecales y E.coli, que deberían estar ausentes según la norma del Comité de Instituciones de Agua Potable y Saneamiento de Centroamérica, Panamá y República Dominicana (CAPRE). De la biopelícula se aisló e identificó bacterias como: Alcaligenes sp, Paenalcaligenes sp, Alcaligenes faecalis, Paenalcaligenes suwonensis, Proteus mirabilis, Serratia nematodiphilia y Stenotrophomona maltophilia, y hongos filamentosos como Apergillus terreus y tres aislados identificados como aspergillus sp. Estos microorganismos se han reportado como responsables de diversas enfermedades transmitidas por el agua.

Palabras claves: Alcaligenes; Serratia; Aspergillus; Microbiología de aguas; Enfermedades transmitidas por agua.

\section{ABSTRACT}

The principal microbiological indicators of the water quality for human consumption were determined by means of the most probable number (NMP) and the isolation joined identification by morphologic and molecular route of the microorganisms isolated from existing biofilm in the point of capture of the aquifer of the community El Cacao, city council Mozonte, Nueva Segovia. Sampling in 3 points: capture, storage and key of jet, and realizing analysis of the NMP, isolations, purification and morphologic tests in the 


\section{L.A Páramo-Aguilera, T.S Garmendia y J. Villalta-Domínguez}

laboratories of the National Program of Investigation Studies and Environmental Services (PIENSA) from National University of Engineering. The microbial sequences were in charge to Molecular Biology of the Central American University. The results indicate pollution by total coliforms, fecal and E.coli, which should be absent according to the norm of The Regional Committee of Institutions of Drinkable Water and sanitation of Central America, Panama and Dominican Republic (CAPRE). Bacterial were isolated from biofilm and identified as: Alcaligenes sp, Paenalcaligenes sp, Alcaligenes faecalis, Paenalcaligenes suwonensis, Proteus mirabilis, Serratia nematodiphilia and Stenotrophomona maltophilia. Filamentous fungi like Apergillus terreus and three isolated identified as aspergillus sp. These microorganisms have been reported in charge of diverse diseases transmitted by the water.

Keywords: Alcaligenes; Serratia; Aspergillus; Water microbiology; Diseases transmitted by water.

\section{INTRODUCCIÓN}

Mozonte cuenta con una red amplia de abastecimiento de agua potable, por medio de mini acueductos rurales que se encuentran ubicados en once comunidades de este municipio. Algunas comunidades: Quisulí Abajo, Los Arados y El Cacao no cuentan con una red de distribución de agua potable. El Cacao se abastece de agua de pozos, quebradas (en invierno) y de un ojo de agua, a través de un sistema instalado que inicia con una pila de captación ubicada en un ojo de agua, su conducción a un tanque de almacenamiento ubicado unos $250 \mathrm{~m}$ aguas abajo de la captación y finalmente una llave de chorro, la cual es el punto de recolección del agua por parte de la población, pero este sistema no cuenta con ningún tipo de tratamiento para potabilizar el agua. La falta de agua apta para el consumo es una fuente directa de enfermedades, por lo que para proteger la salud no basta con tener agua, sino que es imprescindible la aplicación de un tratamiento de potabilización. La capacidad del agua para trasmitir enfermedades depende de su calidad microbiológica y fisicoquímica. Las enfermedades pueden ser causadas por virus, bacterias, hongos e impurezas (Castro, et al., 2014).

La calidad del agua se define por la caracterización de la composición física, química y microbiológica de una muestra de agua, con algunas directrices de la calidad del agua o estándares de tal manera que reúna ciertos criterios sanitarios de aceptabilidad para sus diferentes usos para asegurar la salud pública sin causar ningún daño, y que contenga la proporción adecuada de elementos y sales minerales, pero sin poseer sustancias que pongan en peligro la salud humana en la fisiología normal del organismo (Guzmán, et al., 2015). Según la OMS (2006), la mayor parte de las enfermedades prevalentes en los países en desarrollo, donde el abastecimiento de agua y el saneamiento son deficientes, son causadas por bacterias, hongos, virus y helmintos. La calidad del agua de consumo humano tiene una fuerte incidencia en la salud de las personas, como consecuencia de que sirve como vehículo de muchos microorganismos de orígenes gastrointestinales y patógenos al hombre. Como indicadores de la calidad microbiológica del agua encontramos que los microorganismos Coliformes constituyen un grupo heterogéneo con hábitat primordialmente intestinal para la mayoría de las especies que involucra. El grupo Coliformes es constante, abundante y casi exclusivo de la materia fecal, sin embargo, las características de sobrevivencia y la capacidad para multiplicarse fuera del intestino también se observan en aguas potables, por lo que el grupo Coliformes se utiliza como indicador de contaminación fecal en agua; conforme mayor sea el número de Coliformes en agua, mayor será la probabilidad de estar frente a una contaminación reciente (Mejía, C.M.R. 2005). Por otra parte, la presencia de E. coli en muestras de agua indica la existencia de fallas en la eficacia del tratamiento de aguas e integridad en el sistema de distribución y por tanto es una evidencia de contaminación de diferentes orígenes. Guzmán, et al (2015), destaca que la presencia de Coliformes tanto totales como fecales (E. coli), pueden estar presentes en una fuente de agua durante varias semanas hasta llegar a multiplicarse.

Para la identificación de microorganismos aislados, se parte de considera que la morfología biológica es la disciplina encargada del estudio de la estructura de un organismo y es fundamental en la identificación

Nexo Revista Científica / Vol. 31, No. 01, pp. 01-15 / Junio 2018 


\section{L.A Páramo-Aguilera, T.S Garmendia y J. Villalta-Domínguez}

preliminar y la diferenciación de los microorganismos. La morfología de las bacterias está definida por el tamaño, la forma y la estructura (Tortora, et al., 2010). Según Tortora et al (2010), los hongos son organismos eucarióticos que se caracterizan por presentar una membrana nuclear, además de encontrarse en la naturaleza de manera pluricelular (hongos filamentosos o mohos) o de forma unicelular (levaduras). Este hecho favorece que su material genético se encuentre separado de los demás organelos y pueda realizar divisiones de su núcleo necesarias para la esporulación, que es la principal forma de reproducción de este organismo. Los hongos poseen una estructura de paredes rígidas que rodean el citoplasma, en donde las paredes celulares están compuestas de quitina, sustancia que también se encuentra en el caparazón de cangrejos y langostas. La mayoría de los hongos son aerobios. Entre sus características figuran: formas filamentosas e irregulares, elevaciones umbilicadas (prominencia en el centro de la colonia) y algodonosas, bordes filamentosos, colores fuertes y muy variados.

Los métodos moleculares surgieron como procedimientos complementarios y alternativos para solventar los problemas inherentes presentados por los métodos de identificación microbiana basados en su morfología. La filogenia es el estudio de las relaciones evolutivas entre diferentes grupos de organismos, a partir de la distribución de los caracteres primitivos y derivados en cada taxón utilizando matrices de información de moléculas de ADN y de morfología. Con esta información se establecen los árboles filogenéticos que muestran las relaciones evolutivas entre varias especies u otras entidades que se cree que tienen una ascendencia común, una vez que se resuelve el árbol filogenético del organismo en cuestión y se conocen sus ramas evolutivas, la taxonomía se encarga de estudiar las relaciones de parentesco (Tortora, et al., 2010). Elementos de la morfología microbiana combinados con la aplicación de los métodos moleculares, hoy en día representan una forma rápida y eficaz para la identificación de los microorganismos y que fueron aplicados en el desarrollo de este trabajo.

Estudios previos señalan que las aguas del acuífero del Cacao, poseen varios contaminantes químicos y han propuesto modificaciones para paliar la difícil situación, sin embargo no se conoce de un estudio microbiológico a profundidad que correlacione estado del agua y la presencia de enfermedades que actualmente les azotan analizando el problema de una manera integral. Esta investigación tuvo como objetivo primordial la caracterización microbiológica, incluyendo la especiación de microorganismos presentes en el agua de consumo de la comunidad El Cacao, con el propósito de determinar si existe o no una correlación entre las enfermedades observadas en los pobladores de la comunidad y los microorganismos presentes en el agua de consumo.

\section{METODOLOGÍA}

\subsection{Ubicación del sitio de muestreo}

El sitio de muestreo está situado en la comunidad El Cacao, municipio de Mozonte del departamento de Nueva Segovia, ubicado a $234 \mathrm{~km}$ de la ciudad capital Managua. Las muestras para análisis se tomaron en tres puntos de muestreo descritos en la Tabla 1 y Figura 1.

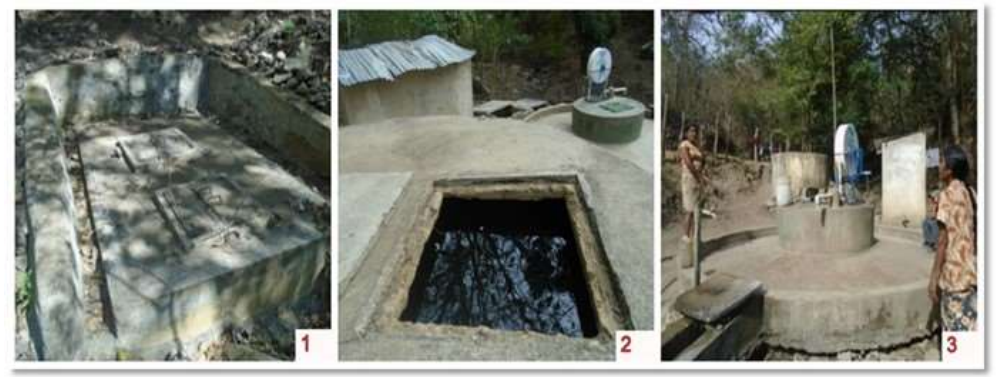

Figura 1. Se muestran los diferentes puntos monitoreados en la comunidad El Cacao.1.Pila de captación, 2. Tanque de almacenamiento, 3.Llave de chorro.

Nexo Revista Científica / Vol. 31, No. 01, pp. 01-15 / Junio 2018 


\section{L.A Páramo-Aguilera, T.S Garmendia y J. Villalta-Domínguez}

Tabla 1. Se relacionan los puntos de muestreo seleccionados para el desarrollo de este trabajo.

\begin{tabular}{cl}
\hline Puntos de muestreo & \multicolumn{1}{c}{ Ubicación } \\
\hline Punto 1 & Pila de captación ubicada en el ojo de agua \\
Punto 2 & $\begin{array}{l}\text { Tanque de almacenamiento ubicado aguas abajo del } \\
\text { sitio de captación }\end{array}$ \\
Punto 3 & $\begin{array}{l}\text { Llave de chorro ubicada en el punto de recolección } \\
\text { del agua por parte de la población }\end{array}$ \\
\hline
\end{tabular}

\subsection{Toma de muestras}

Las muestras de agua fueron recolectadas en bolsas estériles de polietileno Whirl-Pak de $300 \mathrm{~mL}$ utilizando un par de guantes estériles para cada muestra, posteriormente se rotularon las bolsas indicando el sitio de recolección de la muestra, fecha, hora y nombre del muestreador. Luego las muestras fueron trasladadas al laboratorio manteniendo la temperatura de las mismas por debajo de los $10^{\circ} \mathrm{C}$ durante el transporte hasta el laboratorio del PIENSA-UNI en donde fueron procesadas inmediatamente para el caso de la detección de los microorganismos indicadores de la calidad del agua por el método del NMP (Número más probable) y las muestras para aislamiento fueron refrigeradas para su procesamiento al día siguiente.

\subsection{Determinación de la calidad microbiológica del agua.}

Para conocer la calidad microbiológica del agua, se realizó primeramente un análisis a través del método del Número más Probable (NMP), el cual es un método probabilístico de la cantidad de Coliformes totales, Coliformes fecales y Escherichia coli que están contenidas en un volumen determinado de una muestra de agua. Este método consta de dos fases, la fase presuntiva y la fase confirmativa (Tortora et al., 2010). Este análisis se realizó en el Laboratorio de Microbiología del Programa de Investigación Estudios Nacionales y Servicios Ambientales de la Universidad Nacional de Ingeniería (PIENSA-UNI).

Para la prueba presuntiva se hizo diluciones en serie de la muestra de agua. Inicialmente se preparó una dilución primaria, para ello se transfirió $1 \mathrm{~mL}$ de la muestra a un tubo con $9 \mathrm{~mL}$ de agua peptonada de dilución, luego se repitió en serie el procedimiento de dilución hasta alcanzar la dilución $10^{-4}$. Posteriormente se tomó $1 \mathrm{~mL}$ de cada dilución y se agregó a tubos de ensayo que contenían $10 \mathrm{~mL}$ de caldo lauril triptosa y un tubo Durham invertido dentro de estos, el cual es un tubo de fermentación que permite recoger el gas que se produce. Finalmente se agitaron los tubos para homogeneizar la muestra y se introdujeron en una incubadora (Marca MEMMERT, procedencia Alemania) a una temperatura de $35^{\circ} \mathrm{C}$ observándolas después de 48 horas, donde se percibió la formación de gas y turbidez en los tubos de ensayo.

En la fase confirmativa para la búsqueda de Coliformes totales, se transfirió 2 a 3 asadas de cada tubo positivo obtenido durante la prueba presuntiva, a tubos que contenían $10 \mathrm{~mL}$ de caldo de bilis verde brillante con el tubo Durham invertido, luego se agitaron para su homogenización y se incubaron durante 48 horas. Posteriormente se observaron para verificar como positivos aquellos tubos en donde se evidenció gas y turbidez. El mismo procedimiento se realizó para la búsqueda de Coliformes fecales con la diferencia de que se utilizó caldo EC (Medio de cultivo selectivo para determinar la presencia de organismos Coliformes y Escherichia coli), luego se colocaron en el equipo Baño María (Marca MEMMERT, modelo W350T, procedencia Alemania) a una temperatura de $45^{\circ} \mathrm{C}$ por un período de 48 horas hasta observarse la formación de gas y turbidez. Finalmente, la búsqueda de Escherichia coli se 


\section{L.A Páramo-Aguilera, T.S Garmendia y J. Villalta-Domínguez}

realizó siguiendo el mismo procedimiento, pero esta vez se utilizó caldo EC+MUG (Medio de cultivo para la identificación selectiva de Escherichia coli por fluorescencia) ubicando los tubos en baño María a una temperatura de $45^{\circ} \mathrm{C}$ por un lapso de tiempo de 48 horas hasta que se observó la formación de gas y turbidez. Finalmente se utilizó un reflector para verificar fluorescencia porque esto indica la presencia de Escherichia coli en el agua. De acuerdo a los tubos positivos de la prueba confirmativa se consultó la tabla para NMP para conocer el número más probable de microorganismos presentes en las muestras de agua (Guzmán, et al., 2015).

\subsection{Aislamiento e identificación microbiana}

Se aplicó el método de aislamiento e identificación microbiana y tinción Gram, según lo descrito por Rodríguez et al., (2016), basada en la morfología de los microorganismos (bacterias) e identificación morfológica (esporas, color en placas Petri, formas de las esporas) para hongos filamentosos (mohos). Además, se incluyó el método molecular de identificación microbiana (Rodicio y Mendoza, 2004) para conocer el género y la especie de los microorganismos presentes en el agua. A continuación se describe la metodología usada para el método de aislamiento e identificación microbiana con tinción Gram y el método de identificación molecular.

Inicialmente se hicieron dos tipos de medios de cultivos preparados en placas Petri, los cuales fueron: LB (Luria Bertani) para el crecimiento de bacterias y PDA (Potato Dextrosa Agar) para el crecimiento de hongos respectivamente. Luego de la preparación de los medios de cultivos, se tomó $0.1 \mathrm{~mL}$ de la muestra de agua y se inoculó en cada medio correspondiente, posteriormente se esparció la muestra por toda la placa Petri con la ayuda de un bastoncillo de vidrio previamente esterilizado, finalmente se introdujeron en una incubadora a $35^{\circ} \mathrm{C}$ por un lapso de tiempo de 24 a 48 horas aproximadamente. Una vez que se evidenció el crecimiento de microorganismos, las placas fueron retiradas de la incubadora para dar inicio al proceso de aislamiento y purificación de las colonias que se diferenciaban al observarlas al contador de colonia con lupa.

\subsection{Purificación de microorganismos}

Una vez concluida la etapa anterior donde se obtuvieron cultivos mixtos tanto de bacterias como de hongos, se procedió al aislamiento de cada microorganismo hasta determinar que se contaba con cultivos puros, para el caso de las bacterias se utilizó la técnica del estriado de placas (Tortora et al., 2010), mientras que para los hongos filamentosos se realizó un repique de partes (Hifas) de los hongos crecidos y se sembraron en nueva placas Petri conteniendo medio de cultivo PDA por medio de un asa esterilizada. Luego de haber realizado ambos procedimientos, los microorganismos se incubaron a $35^{\circ} \mathrm{C}$ por un periodo de 24 a 48 horas, diariamente se revisaban las placas para determinar el momento en que serían retiradas de la incubadora en función del crecimiento del microorganismo. Finalmente, las bacterias se separaron en 9 grupos por observación visual y se les realizó tinción Gram (Rodríguez et al., 2016), después se observaron por medio de un microscopio óptico binocular con cámara (Marca: OMAX, modelo MD82ES10, procedencia Suiza) en el Laboratorio de Biotecnología de la UNAN-Managua, para identificar las bacterias con base en su morfología como Gram positivas o Gram negativas. Los hongos se observaron al microscopio de luz con un objetivo de 100x (Marca: OLYMPUS CH-2, modelo CHT, procedencia Japón) para conocer la forma y color de las esporas, también se observó visualmente la coloración al frente y reverso de las placas y con esto se determinaron 4 hongos como aislados puros.

\subsection{Análisis de las secuencias e identificación molecular}

Una vez aislados y purificados los microorganismos se procedió a identificarlos por secuenciación haciendo uso del ARN ribosomal $16 \mathrm{~S}$ para el caso de bacterias e ITS 1 para hongos filamentosos. La secuenciación fue solicitada en calidad de servicio al Laboratorio de Biología Molecular de la Universidad

Nexo Revista Científica / Vol. 31, No. 01, pp. 01-15 / Junio 2018 


\section{L.A Páramo-Aguilera, T.S Garmendia y J. Villalta-Domínguez}

Centroamericana (UCA). Con ayuda del programa BioEdit Sequence Alignment Editor versión 7.0, se realizó un análisis de las secuencias a cada electroferograma de cada secuencia cruda, editando cualquier error en las bases nitrogenadas (A, T, G y C) a lo largo de toda la secuencia. Posteriormente cada secuencia nucleotídica obtenida, fueron blasteadas por medio del GenBank del NCBI y alineadas nuevamente haciendo uso del programa Clustal W, para finalmente elaborar el árbol filogenético con el programa MEGA versión 7.0. El análisis de los arboles filogenéticos obtenidos permitió la identificación final de cada microorganismo, contrastando esta información molecular con la información morfológica previamente obtenida.

\section{RESULTADOS Y DISCUSIÓN}

\subsection{Análisis del punto de captación}

Durante el desarrollo de este trabajo se pudo observar que en la pila de captación se forma una biopelícula (figuras 2 A-C). Según Rodríguez et al (2016), una biopelícula es un ecosistema compuesto por uno o varios microorganismos que se adhieren a una superficie gracias a la excreción de una matriz de polímeros extracelulares. Cuando una biopelícula se deja crecer durante un período prolongado de tiempo puede ser lo suficientemente gruesa como para apreciarse a simple vista, ya que algunos microorganismos producen pigmentos que pueden ayudar a la detección visual de la biopelícula por el color que se percibe.

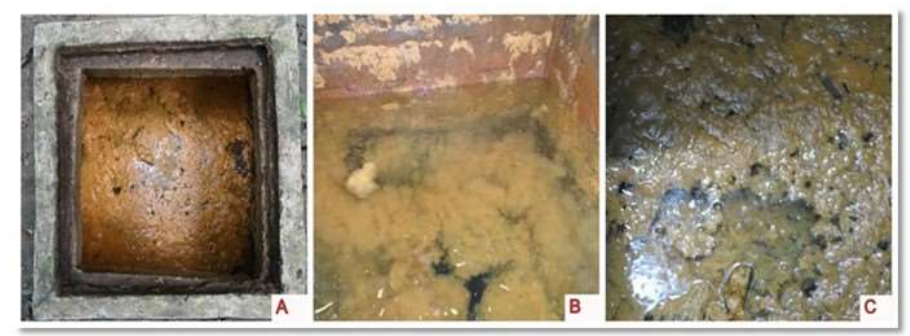

Figura 2. Se muestran diferentes ángulos donde se puede observar la biopelícula que se forma en la pila de captación (punto 1).

La biopelícula en la pila de captación se encuentra dispersa en el agua en forma de una masa amarillenta provocando que el agua permanezca turbia, por tanto, los valores de turbidez particularmente en ese punto resultan alterados. Esta biopelícula se forma en la pila de captación con una rapidez de 8 horas posteriores a la limpieza manual de la misma y más tarde con el tiempo se puede comprobar que coloniza toda la tubería que conduce el agua hasta el tanque de almacenamiento (Figura 1, punto 2), observándose su formación en el mismo tanque y por ende viaja en forma plantónica hasta los hogares una vez que el agua es recogida en la llave de chorro (figura 1, punto 3).

\subsection{Calidad microbiológica del agua analizada}

La tabla 2 muestra los resultados microbiológicos (obtenidos mediante el NMP) de las muestras de agua tomadas en los diferentes puntos muestreados, y se puede comprobar la presencia de coliformes totales, fecales y de E.coli, además esta contaminación se incrementa con el traslado del agua de un lugar a otro, desde el punto de captación (Figura1, punto 1) hasta el punto de abastecimiento de la comunidad (Figura1, punto 3). 
Tabla 2. Resumen de los análisis microbiológicos obtenidos por el método del Número más Probable (NMP), aplicado al agua de consumo de la comunidad El Cacao y comparación con los criterios establecidos en las Normas

CAPRE.

\section{PARÁMETROS MICROBIOLÓGICOS}

\begin{tabular}{|c|c|c|c|c|c|c|c|c|c|c|c|}
\hline \multirow[t]{3}{*}{ Parámetro } & \multirow[t]{3}{*}{ Unidad } & \multicolumn{3}{|c|}{$\begin{array}{c}\text { Pila de } \\
\text { captación } \\
\text { (Punto 1) }\end{array}$} & \multicolumn{3}{|c|}{$\begin{array}{c}\text { Tanque de } \\
\text { almacenamiento } \\
\text { (Punto 2) }\end{array}$} & \multicolumn{3}{|c|}{$\begin{array}{l}\text { Llave de chorro } \\
\text { (Punto 3) }\end{array}$} & \multirow[t]{3}{*}{$\begin{array}{c}\text { Valor } \\
\text { recomendado } \\
\text { por la Norma } \\
\text { CAPRE }\end{array}$} \\
\hline & & \multirow[b]{2}{*}{$1^{\mathrm{o}}$} & \multirow[b]{2}{*}{$2^{\circ}$} & \multirow[b]{2}{*}{$3^{\circ}$} & \multicolumn{3}{|c|}{ Muestreo } & \multirow[b]{2}{*}{$1^{\mathrm{o}}$} & \multirow[b]{2}{*}{$2^{\circ}$} & \multirow[b]{2}{*}{$3^{\circ}$} & \\
\hline & & & & & $1^{\circ}$ & $2^{\circ}$ & $3^{\circ}$ & & & & \\
\hline Coliforme total & $\mathrm{NPM} / 100 \mathrm{~mL}$ & 70 & 79 & 32 & 33 & 130 & 540 & 49 & 1600 & 5400 & Negativo \\
\hline Coliforme fecal & NPM/100mL & 13 & 2.0 & Neg & 14 & 49 & 33 & 17 & 33 & 68 & Negativo \\
\hline E. Coli & NPM/100mL & Neg & 2.0 & Neg & 9.3 & 33 & 6.8 & 13 & 23 & 4.0 & Negativo \\
\hline
\end{tabular}

El grupo Coliforme es un buen indicador microbiano de la calidad del agua potable, debido principalmente a que son fáciles de detectar y enumerar en el agua. El grupo de los Coliformes totales incluye microorganismos que pueden sobrevivir y proliferar en el agua; por consiguiente, no son útiles como índice de agentes patógenos fecales, pero pueden utilizarse como indicador de la eficacia de tratamientos y para evaluar la limpieza e integridad de sistemas de abastecimiento y la posible presencia de biopelículas (Rompré et al., 2002). Los Coliformes fecales comprenden un grupo muy reducido de microorganismos los cuales son indicadores de calidad, ya que son de origen fecal. En su mayoría están representados por el microorganismo E.coli, esta bacteria se encuentra normalmente en el tracto gastrointestinal de los seres humanos y animales de sangre caliente. Debido a su elevada presencia en el tracto gastrointestinal y en las heces, la $E$. coli se utiliza como el indicador principal de contaminación fecal en la evaluación de la inocuidad del agua (OMS, 2006).

Según los resultados del método del Número más probable descritos en la tabla 2, se puede evidenciar la presencia de Coliformes totales, fecales y Escherichia coli en las muestras de agua de la comunidad El Cacao en todos los puntos analizados. Según las normas CAPRE (1994) toda fuente de abastecimiento de agua para consumo humano debe estar libre de la presencia de estas bacterias. El análisis de la tabla 2 para la pila de captación podría estar indicando una contaminación de naturaleza fecal reciente aunque de baja cantidad (Presencia de Coliformes fecales y E.coli) y la presencia permanente de otras bacterias indicadoras de contaminación no muy reciente y que forman parte de los Coliformes totales (Algunos de los cuales podrían estar representados por los microorganismos que fueron identificados por medio de secuenciación). El mismo análisis realizado en el tanque de almacenamiento y la llave de chorro muestran un incremento en los índices de contaminación, lo cual podría estar indicando que el agua se está contaminando aún más durante su recorrido por la tubería hasta el tanque de almacenamiento y de este a la llave de chorro. Esto está en correspondencia con lo que antes fue planteado para la difusión de la biopelícula y con el análisis del entorno observado en el lugar (presencia de animales y fecalismo al aire

Nexo Revista Científica / Vol. 31, No. 01, pp. 01-15 / Junio 2018 


\section{L.A Páramo-Aguilera, T.S Garmendia y J. Villalta-Domínguez}

libre). Las bacterias Coliformes fecales y E.coli son indicadoras por excelencia de contaminación fecal del agua por heces de origen humano. Al analizar la causa de estos resultados, existe la posibilidad que esté relacionada a la defecación al aire libre debido a que un porcentaje de familias carecen de letrina. Estas bacterias al abandonar el cuerpo por medio de las heces e ir al suelo al tener contacto con el agua de lluvia se disuelven y se infiltran hasta llegar al agua del acuífero. Por otra parte, las bacterias Coliformes totales, Coliformes fecales y E.coli son miembros de la familia de las enterobacterias, un grupo de agentes patógenos que causan comúnmente enfermedades gastrointestinales tales como: vómitos, dolor abdominal y diarrea moderada a intensa, además pueden provocar infecciones del tracto urinario, meningitis neonatal, dolores de cabeza, fiebre y daños hepáticos (OMS, 2006). Los pobladores de la comunidad El Cacao afirman que en los últimos años han estado padeciendo de enfermedades entéricas, probablemente debidas al consumo del agua del acuífero con presencia de Coliformes totales, fecales y E.coli. Para eliminar estas bacterias del agua es necesario un proceso de tratamiento.

\subsection{Aislamiento e identificación microbiana por vía morfológica y molecular}

Los trabajos de identificación realizados a nivel morfológico tanto en bacterias como en hongos filamentosos perseguían el objetivo de tener una idea rápida únicamente del tipo de bacteria a nivel de tinción Gram y al mismo tiempo identificar la forma y color de la colonia creciendo en placa Petri con medio de cultivo Luria Bertani (LB). La diferente reacción de las bacterias a la coloración de Gram se relaciona con diferencias fundamentales de la envoltura celular de estas dos clases de células, las bacterias Gram positivas se tiñen de morado ya que el color del cristal violeta se queda atrapado en la capa gruesa de peptidoglicanos que rodea a la célula, mientras que las bacterias Gram negativas tienen una capa de peptidoglicanos mucho más delgada, es por ello que no retienen el cristal violeta y por esto las células se tiñen con safranina y se observan rosadas, Figura 3. Igual que se describió para bacterias anteriormente, en el caso de los hongos filamentosos el objetivo principal era determinar la forma de sus conidias, el color de las mismas, su forma de crecimiento y su color creciendo en placas Petri con medio Potato Dextrose Agar (PDA). En todos los casos se observaron esporas esféricas y los colores que predominaron fueron el blanco y el café (Figura 4 y Tabla 3); los resultados de la observación de las esporas al microscopio de luz con un objetivo de 100x (Marca: OLYMPUS CH-2, modelo CHT, procedencia Japón) permitieron distinguir una primera aproximación al género Aspergillus.

\subsection{Identificación morfológica de bacterias y hongos}

La aplicación de la metodología antes descrita permitió la obtención de 9 aislados puros de bacterias que fueron sometidos a tinción Gram (Figura 3).

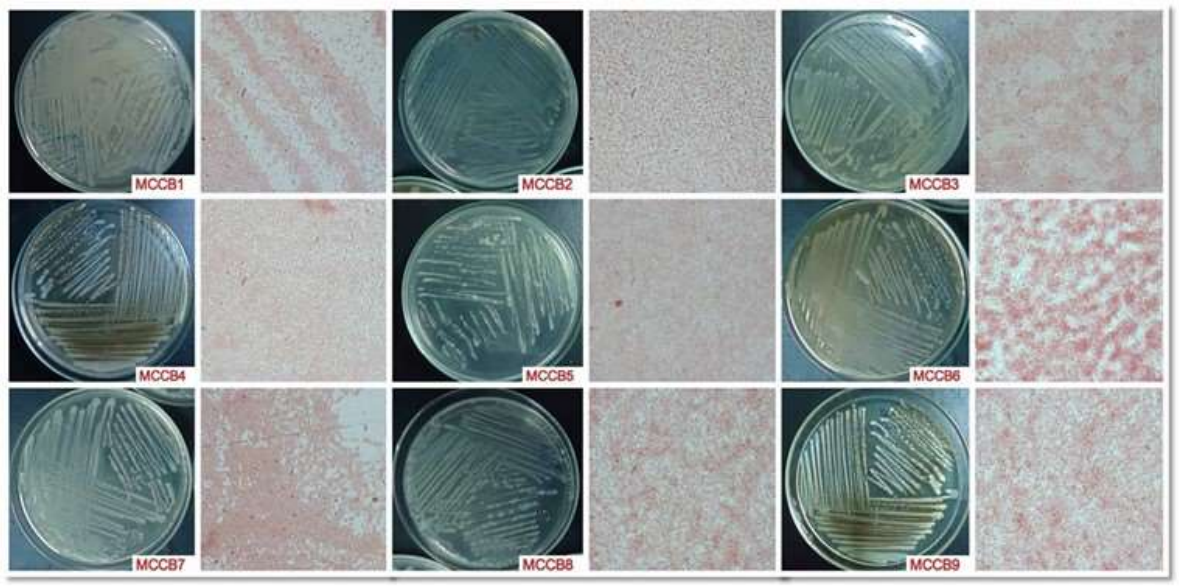

Figura 3. Placas de los aislados puros de bacterias clasificadas como Gram negativas de acuerdo a la reacción a la tinción Gram, en las cuales se puede observar que después de la tinción se tiñeron de color rosado.

Nexo Revista Científica / Vol. 31, No. 01, pp. 01-15 / Junio 2018 
De acuerdo a la reacción a la tinción Gram (Figura 3) las bacterias aisladas fueron clasificadas como Gram negativas, particularmente tenían forma de cocos y bacilos. Esta clasificación coincide con los resultados de las pruebas moleculares, ya que según la información reportada en la literatura (Moon et al., 2014) todas las bacterias identificadas por medio de estas también son Gram negativas. Para el caso de los hongos filamentosos (Figura 4), se obtuvieron 4 aislados diferentes (Arias-Cifuentes y Piñeros-Espinosa, 2008). Cabe mencionar que previo a la identificación por medio de secuenciación, por vía morfológica se llegó a conocer que la cepa MCCI correspondía a Aspergillus niger, de acuerdo a sus características morfológicas tales como el color negro particular de sus colonias; el reverso beige en placa Petri; colonia densa, granular a flocosa (Abarca, 2000). Los tres aislados restantes fueron identificados a nivel de género como Aspergillus sp basado en sus características morfológicas (Tabla 3), posteriormente estos se sometieron a secuenciación para conocer la especie de cada aislado y comparar con la identificación realizada a nivel de género basado en la morfología de los hongos.

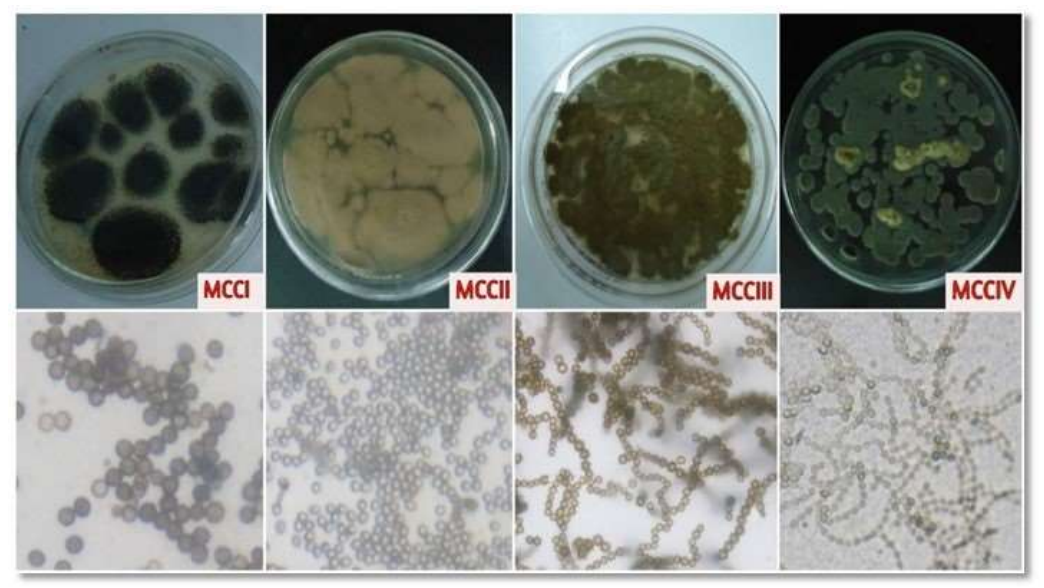

Figura 4. Forma y color de las esporas de los hongos filamentosos aislados de la fuente de agua del Cacao.

Tabla 3: Características morfológicas de los hongos identificados en las muestras de agua de la comunidad El Cacao.

\section{CARACTERÍSTICA}

\begin{tabular}{cllll}
\cline { 2 - 5 } AISLADO & $\begin{array}{c}\text { Forma de las } \\
\text { esporas }\end{array}$ & $\begin{array}{c}\text { Color de las } \\
\text { esporas }\end{array}$ & $\begin{array}{c}\text { Color al frente de } \\
\text { la placa PDA }\end{array}$ & $\begin{array}{c}\text { Color al reverso de la } \\
\text { placa PDA }\end{array}$ \\
\hline MCCI & Esférica & Café oscuro & Negro & Beige \\
\hline MCCII & Esférica & Blanco & Café & Amarillo claro \\
\hline MCCIII & Esférica & Café & Verde & Gris \\
\hline MCCIV & Esférica & Blanco & $\begin{array}{l}\text { Amarillo con centro } \\
\text { verde }\end{array}$ & Amarillo intenso \\
\hline
\end{tabular}

\subsection{Análisis de secuencias e identificación molecular}

La identificación de microorganismos basada en la secuenciación es un método rápido, útil y preciso para la identificación segura de microorganismos. En la actualidad este método tiene un auge muy importante debido a que es específico y puede detectar solo la molécula o microorganismo de interés, además es un método rápido pues puede identificar un microorganismo en un menor tiempo (Ayala et al., 2004). 
Identidad molecular de bacterias: El árbol filogenético de los aislados de bacterias (Figura 5), muestra los diferentes géneros y especies de bacterias aisladas e identificadas en las muestras de agua de la comunidad El Cacao. En el caso de los aislados MCCB5, MCCB6 y MCCB7 solamente se identificaron a nivel de género predominando: Alcaligenes sp y Paenalcaligenes sp; con respecto a los otros aislados se pueden diferenciar especies como: Proteus mirabilis, Serratia nematodiphilia, Paenalcaligenes suwonensis, Alcaligenes faecalis y Stenotrophomona maltophilia. La tabla 4 presenta una correlación entre los resultados obtenidos en la identificación morfológica y la identificación molecular de bacterias.

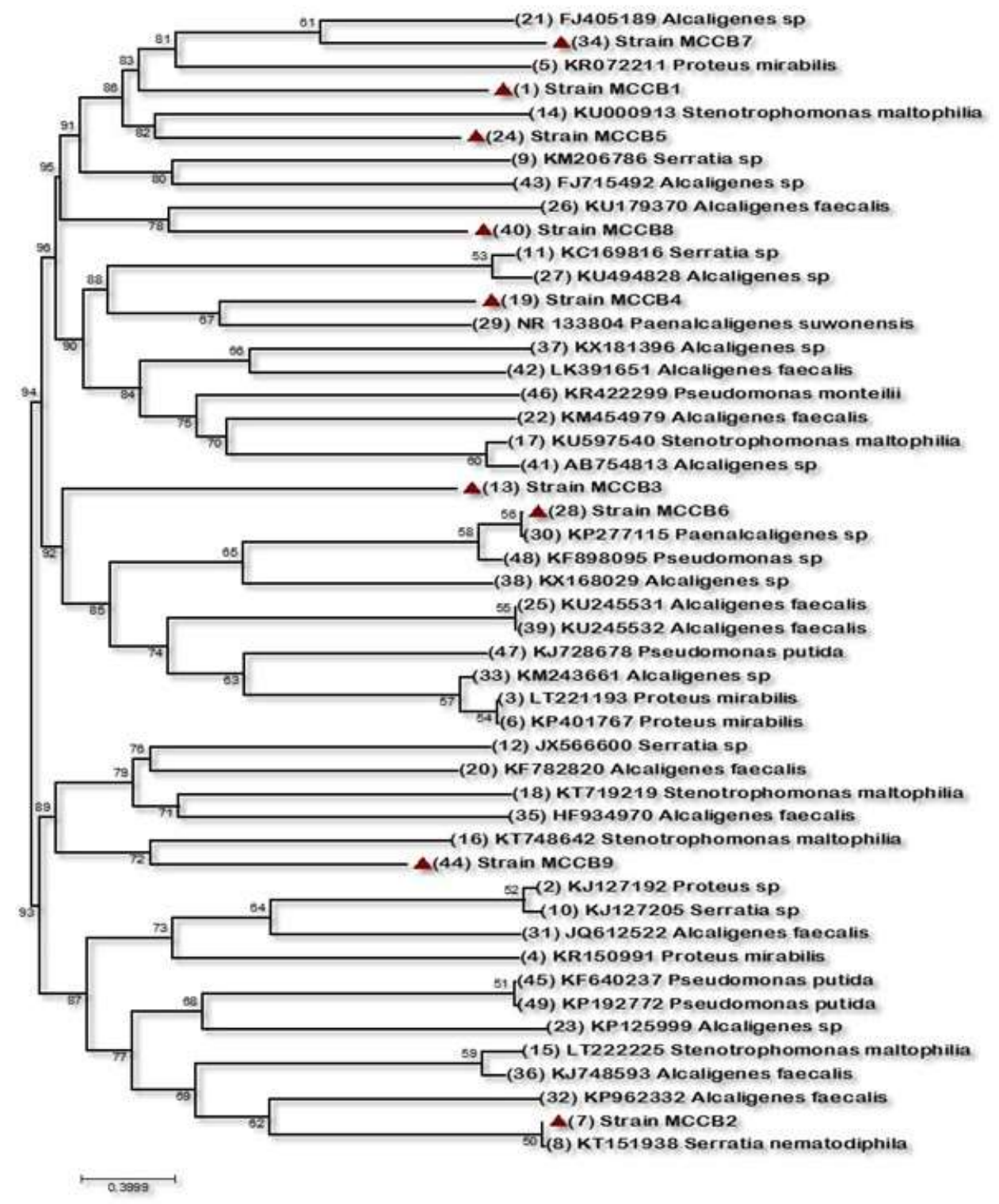

Figura 5. Árbol filogenético de los aislados de las bacterias identificadas por medio de secuenciación provenientes de las muestras de agua de la comunidad El Cacao. 


\section{L.A Páramo-Aguilera, T.S Garmendia y J. Villalta-Domínguez}

Tabla 4. Correlación entre la clasificación morfológica por medio de tinción Gram y los resultados mediante el análisis de la filogenia de bacterias de la figura 5.

\begin{tabular}{|c|c|c|c|c|c|c|}
\hline \multirow[b]{2}{*}{$\begin{array}{l}\mathrm{N}^{0} \text { de } \\
\text { aislado }\end{array}$} & \multirow[b]{2}{*}{$\begin{array}{l}\text { Código } \\
\text { interno }\end{array}$} & \multirow[b]{2}{*}{$\begin{array}{l}\text { Clasificación } \\
\text { morfológica por } \\
\text { tinción Gram }\end{array}$} & \multicolumn{4}{|c|}{ Secuenciación } \\
\hline & & & $\begin{array}{c}\text { BLAST } \\
\text { Max } \\
\text { Score }\end{array}$ & $\begin{array}{c}\text { Max } \\
\text { identidad } \\
(\%)\end{array}$ & Género & Especie \\
\hline 1 & MCCB1 & Gram negativas & 2636 & 98 & Proteus & mirabilis \\
\hline 2 & MCCB2 & Gram negativas & 1653 & 99 & Serratia & nematodiphilia \\
\hline 3 & MCCB3 & Gram negativas & 1465 & 97 & Stenotrophomona & maltophilia \\
\hline 4 & MCCB4 & Gram negativas & 1386 & 99 & Paenalcaligenes & suwonensis \\
\hline 5 & MCCB5 & Gram negativas & 1700 & 99 & Alcaligenes & $s p$ \\
\hline 6 & MCCB6 & Gram negativas & 1301 & 99 & Paenalcaligenes & $s p$ \\
\hline 7 & MCCB7 & Gram negativas & 841 & 98 & Alcaligenes & $s p$ \\
\hline 8 & MCCB8 & Gram negativas & 1718 & 98 & Alcaligenes & faecalis \\
\hline 9 & MCCB9 & Gram negativas & 1703 & 98 & Stenotrophomona & maltophilia \\
\hline
\end{tabular}

Según Moon et al., 2014, Alcaligenes es un género de bacterias Gram negativas y aeróbicas que se pueden encontrar en el agua o suelo. Alcaligenes faecalis es la especie más frecuente del género Alcaligenes, su nombre se debe a que su descubrimiento se realizó en heces pero más tarde se ha documentado su presencia en muchos otros entornos como en el suelo, el agua, la flora intestinal humana y los ambientes hospitalarios. La infección sistémica con este organismo es muy poco frecuente, se ha notificado que causa casos esporádicos de otitis crónica, infección de las vías urinarias y bacteriemia. El género Paenalcaligenes está filogenéticamente relacionada con el género Alcaligenes. Paenalcaligenes suwonensis es una especie novedosa dentro del género Paenalcaligenes, suwonensis se refiere a la región de Suwon de la República de Corea donde fue encontrada; esta bacteria es aeróbica y Gram negativa, es causante de infecciones en las vías urinarias e infecciones en el oído (Moon et al., 2014; Kämpfer et al., 2010). Proteus mirabilis es un bacilo Gram negativo aerobio facultativo, se encuentra comúnmente en el tracto intestinal humano, es un importante agente causal de infecciones del tracto urinario, también puede causar infecciones en heridas y bacteriemia en pacientes debilitados. El tratamiento convencional suele ser mediante antibióticos, pero debido a la tremenda resistencia que tiene la bacteria muchas veces son necesarias varias cargas de los mismos para neutralizarla (Ji-Young et al., 2014).

Serratia nematodiphilia es una bacteria entérica, se denomina así porque con mucha frecuencia se encuentran en el tracto intestinal (entérico) de animales superiores, sin embargo se conoce también que se encuentra libre en el agua y en el suelo. Serratia nematodiphilia son bacilos Gram negativos pequeños y anaerobios facultativos, es un patógeno oportunista causante frecuente de infecciones nosocomiales (intrahospitalarias), otras enfermedades que causa esta bacteria son: neumonías, bacteriemia, infecciones de las vías urinarias e infecciones en heridas (Kämpfer et al., 2010). De acuerdo a Kämpfer et al., (2010), Stenotrophomona maltophilia es un bacilo aerobio Gram negativo que se encuentra en ambientes acuáticos. Este microorganismo se ha asociado a infecciones nosocomiales y bacteriemia, además puede ocasionar lesiones de piel y tejidos blandos, infecciones óseas y gastrointestinales. En entrevistas con los pobladores de la comunidad algunos afirmaron que comúnmente tenían enfermedades diarreicas y respiratorias y se evidenció in situ la presencia de manchas blancas en la piel en adultos y niños. Estas 


\section{L.A Páramo-Aguilera, T.S Garmendia y J. Villalta-Domínguez}

enfermedades pudieran estar relacionadas con la presencia de estas bacterias en el agua de consumo y deberá ser un factor de interés a investigar por parte de los sistemas locales de salud, así como de los órganos de gobierno a nivel municipal.

Identidad molecular de hongos: Los 4 aislados puros de hongos que se obtuvieron del aislamiento, fueron secuenciados por ITS1 y para su análisis se siguió el mismo procedimiento que se utilizó para las bacterias. Por medio del árbol filogenético de hongos filamentosos (Figura no mostrada en este trabajo) y por la tabla 5 se hizo una comparación entre la identificación de hongos basado en la morfología (Tabla 3) y los resultados de la secuenciación.

Tabla 5. Comparación de la identificación de hongos mediante información morfológica con los resultados de las pruebas moleculares

\begin{tabular}{ccccccc}
\hline & & & \multicolumn{4}{c}{ Secuenciación } \\
\cline { 4 - 6 } $\begin{array}{c}\mathbf{N}^{\mathbf{0}} \mathbf{d e} \\
\text { aislado }\end{array}$ & $\begin{array}{c}\text { Código } \\
\text { interno }\end{array}$ & $\begin{array}{c}\text { Identidad } \\
\text { morfológica }\end{array}$ & $\begin{array}{c}\text { BLAST } \\
\text { Max Score }\end{array}$ & $\begin{array}{c}\text { Max } \\
\text { identidad } \\
\mathbf{( \% )}\end{array}$ & Género & Especie \\
\hline 1 & MCCI & Aspergillus Niger & 1123 & 99 & Aspergillus & tamarii \\
2 & MCCII & Aspergillus $s p$ & 1000 & 99 & Aspergillus & terreus \\
3 & MCCIII & Aspergillus $s p$ & 946 & 99 & Aspergillus & $s p$ \\
4 & MCCVI & Aspergillus $s p$ & 990 & 99 & Aspergillus & $s p$ \\
\hline
\end{tabular}

Según la comparación de la identificación morfológica con la identidad obtenida por vía secuenciación (Tabla 5), se obtuvo una coincidencia entre identificación morfológica de género y los resultados de las pruebas moleculares de hongos a este mismo nivel. El aislado MCCII se logró identificar en las pruebas moleculares hasta nivel de especie como terreus, con alto porcentaje de identidad de $99 \%$, a diferencia de los aislados MCCIII y MCCIV que solamente fueron posibles identificarlos hasta nivel de género como Aspergillus sp, al igual que la identificación basada en la morfología. El análisis del árbol filogenético para este caso mostró que MCCI, aparece claramente entre el grupo de Aspergillus tamarii contradiciendo lo que morfológicamente habíamos comprobado y lo que nos indica la bibliografía (Arias-Cifuentes y Piñeros-Espinosa 2008). Es debido a lo anterior que se prefirió dejar su identificación hasta el nivel de género (en el que si hay coincidencia) y pruebas posteriores definirán una identificación hasta el nivel de especie.

Según Cuenca-Estrella (2012), el género Aspergillus es un hongo de distribución universal, está presente en el suelo, aire, agua, plantas y materia orgánica en descomposición; su desarrollo se ve favorecido por la humedad y las temperaturas elevadas, ya que es termotolerante y puede vivir entre $\operatorname{los} 12^{\circ} \mathrm{C}$ y $\operatorname{los} 57^{\circ} \mathrm{C}$. Es un patógeno oportunista, es decir, que suele afectar a pacientes con mecanismos de defensa comprometidos.

Se ha descrito (Samson et al., 2007) que hongos filamentosos pertenecientes al género Aspergillus causan infecciones locales tales como la otomicosis y queratitis; e infecciones superficiales como la onicomicosis, además puede producir infecciones invasivas como la aspergilosis, la cual es una reacción alérgica que generalmente se desarrolla en personas que ya tuvieron problemas pulmonares, como asma o fibrosis quística y el aspergiloma, que es un tumor (bola fúngica) que se desarrolla en una zona de enfermedad pulmonar o cicatrización pulmonar. Aspergillus niger es fácil de distinguir ya que las colonias de esta especie son de color negro-púrpura a negro. Se ha observado en una amplia gama de hábitats porque pueden colonizar una variedad de sustratos. Este hongo es un serio patógeno humano ya que puede causar 


\section{L.A Páramo-Aguilera, T.S Garmendia y J. Villalta-Domínguez}

graves infecciones en los pulmones, tejidos paranasales, piel y uñas (Reyes et al., 2013). Aspergillus terreus se distingue fácilmente de las otras especies de Aspergillus por su coloración de colonia canelamarrón. Son causas de infección en personas con sistemas inmunológicos deficientes, además causa infección respiratoria típica y otras infecciones como onicomicosis y otomicosis (Baddley et al., 2003).

La mayoría de los hongos identificados en este trabajo mediante las pruebas moleculares son causantes de enfermedades infecciosas que afectan principalmente a adultos mayores y niños. En los pobladores de la comunidad El Cacao se evidenció que tenían infecciones en las uñas, además los pobladores afirmaron que muchos de ellos presentaban problemas oculares como ceguera e inflamación de la córnea, quizás la causa de estas enfermedades podría estas asociada con el agua de consumo que estos pobladores están recibiendo, ya que se demuestra por estos resultados que hongos del género Aspergillus fueron localizados como parte de la comunidad microbiana que forman la biopelícula localizada en el punto de captación de agua del cual se abastece la comunidad El Cacao. Estos resultados, al igual que los antes mostrados en bacterias provenientes de la misma biopelícula, deberán ser de gran interés para los encargados del sector salud y los entes gubernamentales que velan por el bienestar de esta comunidad.

\section{CONCLUSIONES}

El desarrollo de esta investigación realizada en el sistema de abastecimiento de agua de la comunidad El Cacao nos permitió obtener los siguientes resultados que se destacan: Con respecto a los análisis microbiológicos se determinó mediante el método del Número más probable (NMP) la presencia de Coliformes totales, fecales y E. Coli en el agua de consumo de la comunidad El Cacao. Según las normas CAPRE los resultados de estos parámetros tienen que ser negativos, por tanto las aguas de este acuífero, no cumplen con las Normas CAPRE. Por medio del aislamiento e identificación microbiana se obtuvieron 9 aislados puros de bacterias que fueron clasificadas por la reacción a la tinción Gram como Gram negativas. Se obtuvieron 4 aislados puros correspondientes a hongos filamentosos, identificándose basado en la morfología a uno de ellos a nivel de especie como Aspergillus niger y a los tres restantes como pertenecientes al género Aspergillus. Los análisis moleculares y la aplicación de la filogenia permitió identificar a las bacterias aisladas como: Alcaligenes sp, Paenalcaligenes sp, Alcaligenes faecalis, Paenalcaligenes suwonensis, Proteus mirabilis, Serratia nematodiphilia y Stenotrophomona maltophilia. De igual forma se identificó a los hongos filamentosos como: Aspergillus sp y Aspergillus terreus. La bibliografía consultada refiere que estas bacterias y hongos son causantes de enfermedades diarreicas, respiratorias e infecciosas, entre otras, mismas que los pobladores afirman que están padeciendo y por ende los resultados de este trabajo podrían resultar de interés para personal encargado del sector salud y entes gubernamentales encargados de velar por el bienestar de la comunidad.

\section{NOMENCLATURA}

$\begin{array}{ll}\text { NMP } & \text { Número más probable } \\ \text { PIENSA } & \text { Programa de Investigación Estudios Nacionales y Servicios Ambientales. } \\ \text { UNI } & \text { Universidad Nacional de Ingenierías. } \\ \text { CAPRE } & \text { Comité Coordinador Regional de Instituciones de Agua Potable y Saneamiento de } \\ & \text { Centroamérica, Panamá y República Dominicana, en adelante "CAPRE" } \\ \text { ADN } & \text { Acido Desoxirribonucleico } \\ m L & \text { mililitros } \\ \text { Caldo EC } & \text { Caldo Escherichia coli } \\ \text { Caldo EC+MUG } & \text { Caldo Escherichia coli }+ \text { elementos para la identificación selectiva de E.coli por } \\ & \text { fluorescencia. } \\ L B & \text { Luria Bertani } \\ P D A & \text { Papa Dextrosa Agar } \\ \text { ARN } & \text { Ácido ribonucleico }\end{array}$




\title{
L.A Páramo-Aguilera, T.S Garmendia y J. Villalta-Domínguez
}

\author{
ITS Internal Transcribed Spacer \\ UCA Universidad Centro Americana \\ NCBI National center for Biotechnology
}

\section{AGRADECIMIENTOS}

Los autores desean patentizar su agradecimiento a la Universidad Nacional de Ingeniería (UNI), quien por medio de su vicerrectoría de investigación y desarrollo, las convocatorias a ferias Tecno-UNI y su programa de apoyo para el desarrollo de tesis de grado, contribuyeron apreciablemente al financiamiento para el desarrollo de este trabajo. Especial agradecimiento al Programa de Investigación Estudios Nacionales y Servicios al Ambiente (PIENSA/UNI), quien por medio de sus laboratorios realizaron los diferentes análisis y pruebas que se desarrollaron en este trabajo, financiando además con sus propios recursos todos los gastos relacionados con el proceso de muestreo a la comunidad El Cacao. Nuestra gratitud al personal de Laboratorios PIENSA y a la Alcaldía de Mozonte que nos acompañaron por medio de sus técnicos durante la recopilación de la información y muestreos a la zona.

\section{REFERENCIAS}

Abarca, M. (2000). Taxonomía e identificación de especies implicadas en la aspergilosis nosocomial. Revista iberoamericana de micología, 17, S79-S84.

Arias-Cifuentes, E. L y Piñeros-Espinosa, P. A. (2008). Aislamiento e identificación de hongos filamentosos de muestras de suelo de los Paramos de Guasca y Cruz verde. Trabajo de grado presentado como requisito parcial para optar al título de microbiología industrial. Pontificia Universidad Javeriana, Facultad de ciencias, carrera de Microbiología industrial, Bogotá.

Ayala, L., Rodríguez, R., Aguilar, C., Lara, F y Quero, A. (2004). Detección de Clavibacter michiganensis subspnebraskensis usando la reacción en cadena de la polimerasa. Revista Fitopatología Mexicana, 22 (2), 239-245.

Baddley, J., Pappas, P., Smith, A and Moser, S. (2003). Epidemiology of Aspergillus terreus at a University Hospital. Journal of clinical microbiology, 41 (12), 5525-5529.

Castro, M., Almeida, J., Ferrer, J y Díaz, D. (2014). "Indicadores de la calidad del agua: evolución y tendencias a nivel global". Ingeniería Solidaria, 10 (17), 111-124.

Cuenca-Estrella, M. (2012). Diagnóstico de laboratorio de la enfermedad fúngica invasora. Microbiología Clínica, 30 (5), 257-264.

Guzmán, B.L., Nava, G y Díaz, P. (2015). La calidad del agua para consumo humano y su asociación con la morbilidad en Colombia, 2008-2012. Biomédica, 35 (2), 177-190.

Ji-Young, M., Jun-Muk, L., Jae-Hyung, A., Hang-Yeon, W., Soon-Wo, K and Soo-Jin, K. (2014). Paenalcaligenes suwonensis sp.nov., isolated from spent mushroom compost. Int J Syst Evol Microbiol, 64, 882-886.

Kämpfer, P., Falsen, E, Langer, S, Looderss, N \& Busse, H. (2010). Paenalcaligenes hominis gen.nov. a new member of the family Alcaligenaceae. Int J Syst Evol Microbiol, 60, 1537-1542. 
Mejía, C.M.R. (2005). Análisis de la calidad del agua para consumo humano y percepción local de las tecnologías apropiadas para su desinfección a escala domiciliaria, en la microcuenca El Limón, San Jerónimo, Honduras. Tesis sometida a consideración de la Escuela de Postgrado, Programa de Educación para el Desarrollo y la Conservación del Centro Agronómico Tropical de Investigación y Enseñanza como requisito para optar por el grado de: Magíster Scientiae en Manejo Integrado de Cuencas Hidrográficas. Turrialba.

Moon, J., Lim, J., Ahn, J., Weon, H., Kwon, S and Kim, S. (2014). Paenalcaligenes suwonensis isolated from spent mushroom compost. Journal of Systematic and Evolutionary Microbiology, 64, 882-886.

Normas CAPRE. (1994).Normas de calidad del agua para consumo humano. Primera Edición. COMITÉ COORDINADOR REGIONAL DE INSTITUCIONES DE AGUA POTABLE Y SANEAMIENTO DE CENTROAMÉRICA, PANAMA Y REPÚBLICA DOMINICANA. APARTADO POSTAL 404-2010 ZAPOTE, SAN JOSE COSTA RICA. TEL (506) 222-4456.; FAX (506) 2552771.

Organización Mundial de la Salud (OMS). (2006). Guías para la calidad del agua potable. Primer Apéndice a la Tercera Edición. Volumen 1. Recomendaciones de la Organización Mundial de la Salud (OMS). ISBN 9241546964 (Clasificación de la NLM: WA 675). Versión Electrónica para la web. http//www.who. intwater_sanitation_healthdwqgdwq3_es_fulll_lowsres.pdfua $=1$

Reyes, I., González, M y López, F. (2013) Un análisis del metabolismo de Aspergillus niger creciendo sobre un sustrato sólido. Rev. Mex. Ing. Quím, 12 (1), 41-56.

Rodríguez, C. E., Gamboa, C. M. del M., López, U. D., Quesada, G.C y Rodríguez, S.C. (2016). Bacteriología general: principios y prácticas de laboratorio. Segunda edición. ISBN: 9789968465779. Editorial Universidad de Costa Rica. Costa Rica.

Rodicio, M del M y Mendoza, M del C. (2004). Identificación bacteriana mediante secuenciación del ARNr 16S: fundamento, metodología y aplicaciones en microbiología clínica. Enferm Infecc Microbiol Clin, 22 (4), 238-245

Rompré, A., Servais, P., Baudart, J.,Roubin, M and Laurent, P. (2002). Detection and enumeration of coliforms in drinking water: Current methods an emerging approaches. Journal of Microbiological Methods, 49 (1), 31-54.

Samson, R., Noonim, P., Meijer, M., Houbraken, J., Frisvad, J and Varga, J. (2007). Diagnostic tools to identify black aspergillus. Journal Studies in Mycology, 59 (13), 129-145.

Tortora, G.J, Funke, B.R and Case, C.L. (2010). Mycrobioly an Introduction. Tenth Edition. PEARSON.

\section{SEMBLANZA DE LOS AUTORES}

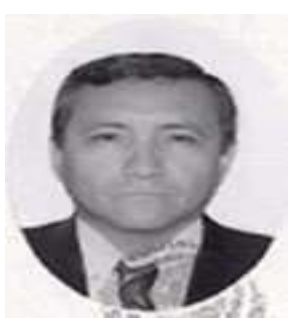

Leandro Alberto Páramo Aguilera, Graduado como Ingeniero Químico con maestría en Ingeniería Química y énfasis en procesos biotecnológicos, en el Instituto Superior Politécnico "José Antonio Echeverría", ISPJAE, de la Ciudad de la Habana, Cuba, en el año 1990. En 1997 se gradúa como Master en Microbiología y énfasis en bacteriología en la Universidad de Costa Rica, UCR. En junio del 2012, se gradúa como Doctor en Ciencias en el área de Biotecnología en el Centro de Biotecnología Genómica (CBG) del Instituto Politécnico Nacional (IPN) de México. Amplia experiencia en el desarrollo de procesos biotecnológicos (biofertilizantes, bebidas alcohólicas, fermentados lácteos, bioprospección, compostaje, etc). 